\title{
POLÍTICAS LINGUÍSTICAS E TRADUÇÃO-INTERPRETAÇÃO DE LÍNGUAS DE SINAIS: APROXIMAÇÕES ENTRE BRASIL E MOÇAMBIQUE
}

\author{
LANGUAGE POLICIES AND SIGN LANGUAGE TRANSLATION AND INTERPRETING: \\ CONNECTIONS BETWEEN BRAZIL AND MOZAMBIQUE
}

Silvana Aguiar dos Santos Professora Adjunta no Departamento de Artes e Libras da Universidade Federal de Santa Catarina aguiar.sil@gmail.com

Nehemia Gilberto Raul Zandamela Universidade Eduardo Mondlane, Faculdade de Educação, Moçambique nehemia.gil@gmail.com

Resumo: Este trabalho resulta de uma aproximação inicial entre Brasil e Moçambique no que tange à tradução e à interpretação de línguas de sinais. Retomamos alguns marcos históricos importantes nas políticas linguísticas voltadas às línguas de sin desses países e discutimos como determinadas ações afetam diretamente as decisões políticas direcionadas à tradução e à interpretação de línguas de sinais. Diante desse cenário, são apresentadas duas vertentes de argumentação. A primeira delas discute algumas implicações da tradução e da interpretação de línguas de sinais para o cenário lusófono, uma vez que o português é língua oficial nos dois países. A segunda linha aborda algumas reflexões sobre os movimentos surdos e os movimentos de tradutores e intérpretes de línguas de sinais, o reconhecimento legal das línguas de sinais, assim como a criação dos cursos de graduação e os desafios contemporâneos da atuação dos profissionais da tradução. Por fim, sugere-se que os tradutores e intérpretes de línguas de sinais, tanto do Brasil quanto de Moçambique, realizem esforços junto às instâncias governamentais para que destinem investimentos: (i) à formação por contextos especializados de tradução e interpretação, (ii) à qualificação dos serviços ofertados por esses profissionais e (iii) à formação de recursos humanos nos níveis de mestrado e doutorado a fim de fortalecer a pesquisa sobre tradução e interpretação de línguas de sinais na Comunidade dos Países de Língua Portuguesa (CPLP).

Palavras-chave: Políticas linguísticas; Línguas de sinais; Tradução-Interpretação. 
Abstract: This paper is the result of an initial attempt to establish a connection between Brazil and Mozambique regarding sign language translation and interpreting. It reviews some important landmarks in language policies aimed at sign languages in these countries and discusses how certain actions directly impact political decisions related to sign language translation and interpreting. In this context, two lines of argument are developed. The first one addresses the role of sign language translation and interpreting in the Portuguese-speaking context, since Portuguese is the official language in both countries; the other offers some reflections about the Deaf movements and the movements of sign language translators and interpreters, the legal recognition of sign languages, the development of undergraduate courses and the contemporary challenges in the work of translation professionals. Finally, it is suggested that sign language translators and interpreters in both Brazil and Mozambique undertake efforts to press government bodies to invest in: (i) area-specific training for translators and interpreters, (ii) qualification of the services provided by such professionals, and (iii) development of human resources at master's and doctoral levels in order to strengthen research on sign language translation and interpreting in the Community of Portuguese-Speaking Countries.

Keywords: Language Policies; Sign Languages; Translation-Interpreting.

\section{Introdução}

Nos últimos anos, as discussões sobre língua, multilinguismo, poder, discursos e políticas conquistaram uma visibilidade maior não só nas práticas sociais, nas quais diferentes comunidades começaram a exigir e exercer seus direitos linguísticos, mas também na produção acadêmica sobre aspectos relacionados a esses temas e às políticas linguísticas. As decisões em torno das línguas, das tensões e dos conflitos enfrentados por diferentes comunidades linguísticas, ou ainda das políticas linguísticas construídas diante desses contextos, revelam diferentes perspectivas ideológicas, que podem cooperar para a promoção dessas línguas ou para oprimir mais ainda os falantes dessas comunidades interculturais. 
Behares (2012) menciona algumas dessas ideologias sobre as línguas: a dos filólogos, a dos linguistas, a dos sociólogos e antropólogos sociais, a dos governos e administradores de estados, a dos comerciantes, a das comunidades linguísticas e a dos professores. Ou seja, essas diversas perspectivas ideológicas operam de alguma forma nas políticas linguísticas adotadas por um determinado país, seja na indústria da língua, na concepção de ensino-aprendizagem das diferentes línguas, nas reivindicações apresentadas pelos falantes ou ainda nas políticas de tradução adotadas pelos governos.

As articulações entre políticas linguísticas e políticas de tradução são bastante recentes no meio acadêmico e pouco exploradas enquanto objeto de pesquisa, embora o ofício de traduzir ou interpretar seja evidente nas interações de comunidades que compartilham de línguas diferentes. Dessa forma, a espinha dorsal deste trabalho centra-se nas aproximações entre Brasil e Moçambique permeadas pela tradução e pela interpretação de línguas de sinais. Ou seja, buscam-se alguns marcos históricos importantes nas políticas linguísticas voltadas às línguas de sinais desses países e discute-se como determinadas ações afetam diretamente os encaminhamentos direcionados à tradução e à interpretação de línguas de sinais.

Diante desse cenário são apresentadas duas vertentes de argumentação. A primeira delas discute algumas aproximações entre Brasil e Moçambique permeadas pela lusofonia ${ }^{1}$ e questões de tradução e interpretação de línguas de sinais. A segunda linha de argumentação aborda algumas reflexões sobre os movimentos surdos e os movimentos de tradutores e intérpretes de línguas de sinais, o reconhecimento legal das línguas de sinais, assim como a criação de cursos de graduação. Por fim, discutimos os desafios contemporâneos da atuação dos profissionais da tradução.

Ao longo do texto, busca-se estabelecer um elo de discussão que considere a tradução e a interpretação como um elemento importante sobre o qual é preciso refletir nas

\footnotetext{
${ }^{1}$ Neste texto, adotamos o conceito de lusofonia entendido como países que utilizam a língua portuguesa como oficial. Não realizamos uma discussão crítica e profunda sobre o que o termo lusofonia implica, dado que o objetivo deste trabalho centra-se no resgate histórico de alguns elementos relevantes para a tradução e a interpretação das línguas de sinais. No entanto, partilhamos da concepção adotada por Severo e Makoni (2015, p. 17, de que "a partir do século XVI houve uma série de empreitadas coloniais exploratórias centradas na Europa - como lusofonia, hispanofonia, anglofonia e francofonia-, que carregaram consigo projetos políticos, econômicos e culturais. Essas empreitadas se constituíram em torno de uma dada concepção de língua, nação e cultura, conduzindo processos violentos de apropriação, dominação e subjugação de pessoas, terras e culturas.”
} 
pesquisas de modo geral, especialmente, aquelas que tratam sobre políticas linguísticas. A tradução e a interpretação das línguas de sinais podem oferecer ricas possibilidades de articulação teórica e empírica, mostrando que o espaço das línguas nacionais precisa ser visibilizado, mesmo que uma política de lusitanização esteja em jogo.

\section{Aproximação inicial entre Brasil e Moçambique: a lusofonia e questões de tradu- ção e interpretação de línguas de sinais ${ }^{2}$}

Em consulta realizada ao volume completo do Anuário dos Colóquios da Lusofonia $^{3}$, referente aos anos de 2002 a 2010, não foram encontrados registros sobre as línguas de sinais. Nesse anuário, o índice de ocorrência para a palavra "tradução" é bastante significativo, sendo que o termo aparece 620 vezes no texto. Algumas dessas ocorrências mencionam a tradução de obras literárias, a legendagem e a dublagem, a lusofonia e a problemática da tradução, dentre outras. Já, ao consultarmos as ocorrências para a palavra "intérprete", os números são bastante reduzidos, registrando apenas 26 ocorrências no referido documento (anuário).

Esse registro inicial das ocorrências sinaliza um espaço pouco visível para as pesquisas sobre tradução e interpretação de línguas no mundo lusófono, o que sugere algumas implicações. Talvez, em um primeiro momento, discutir o papel da tradução ou da interpretação de línguas, de modo geral, em comunidades que têm uma ou várias línguas oficiais pareça ser uma contradição. Por outro lado, a tradução e a interpretação são atividades que ganham visibilidade institucional na medida em que as línguas também conquistam esse status. Muitas dessas demandas podem ser invisíveis e não estar presentes nas pautas governamentais. Ngunga (2014) reflete sobre uma situação que de certa forma se articula com a temática da tradução e da interpretação:

[...] Eu não sei como é que uma pessoa se sente quando é julgada numa língua que não percebe. De repente, sucede que ela se encontra numa cela sem saber as razões, porque o juiz a julgou utilizando um idioma estranho e, nesse caso, ela nem percebeu o que aconteceu. Portanto, a língua é um

\footnotetext{
${ }^{2}$ Somos gratos pelas contribuições da professora Ezra Chambal Nhampoca, que explanou alguns desafios sobre as questões de línguas e multilinguismo em Moçambique.

${ }^{3}$ Os anuários constituem-se como publicações resultantes dos Colóquios de Lusofonia. Os colóquios ocorrem anualmente em diferentes países que possuem a língua portuguesa como idioma oficial. Para mais informações, consultar Chrystello (2002).
} 
instrumento muito importante na nossa vida como pessoas que vivem numa sociedade. Penso que cada pessoa devia respeitar a língua materna do outro, enquanto direito humano de se comunicar e de se defender, porque é a partir dela que isso se faz da melhor forma. (NGUNGA, 2014, $\mathrm{s} / \mathrm{p})$.

Embora Ngunga (2014) não mencione o papel do tradutor ou do intérprete na esfera jurídica para casos como o depoimento acima, tal profissional favorece, por meio dos serviços de tradução ou de interpretação, a garantia de direitos linguísticos para pessoas não falantes da língua oficial de um determinado país. Por exemplo, apesar de a língua portuguesa ser o idioma oficial de Moçambique, as línguas de origem bantu são compartilhadas como primeira língua pela maioria dos cidadãos daquele país. Ou seja, línguas como Makhuwa, Changana, Sena, Lomwe, Nyanja, Chuwabu, Ndau, Tshwa, Nyungwe, Rhonga e Tonga, dentre outras, fazem parte do cotidiano do povo moçambicano. Não é por acaso que Severo, Sitoe e Pedro (2014) publicaram uma obra intitulada Estão as linguas nacionais em perigo?

As discussões realizadas até o presente momento sinalizam para a relação entre a língua portuguesa e as outras línguas nacionais em Moçambique como um fator importante para visibilizar a tradução ou a interpretação de diversas línguas. No país africano, as traduções e as interpretações podem constituir-se como uma prática comum, porém pouco investigada ou debatida na literatura científica. Em contrapartida, as articulações entre lusofonia e ensino de língua, ou questões relacionadas ao letramento em língua portuguesa, são temas bastante frequentes nas pesquisas e ações governamentais. Essa observação também se reflete na área das línguas de sinais. O campo da tradução e da interpretação de línguas de sinais na Comunidade dos Países de Língua Portuguesa (CPLP) parece pouco investigado, ao passo que o ensino de língua portuguesa para pessoas surdas é registrado com frequência nas publicações acadêmicas e ações governamentais. As questões relacionadas à lusofonia e à sua relação com o ensino de língua portuguesa para surdos foi tratada por Salles et Al. (2004):

Cinco séculos depois da colonização, nos primeiros anos do $2^{\circ}$ milênio, a sociedade brasileira se apresenta como maior nação de falantes de língua portuguesa. No entanto, sua liderança no bloco lusófono deverá afirmarse pela valorização da língua portuguesa como fator de união e solidariedade na comunidade lusófona, com o respeito à diversidade lingüística e 
à expressão multicultural dos povos. Para tanto, é necessário promover o letramento e o amplo acesso do cidadão às diferentes instâncias sociais, à produção e ao usufruto dos bens culturais e artísticos, com vistas ao desenvolvimento humano e à realização pessoal. A situação da comunidade surda nesse cenário é particularmente interessante, em termos lingüísticos, pela perspectiva do bilinguismo, e culturais, tanto no plano da cidadania brasileira, com o sentimento de nacionalidade e o respaldo institucional, quanto na condição que identifica seus membros como detentores de uma cultura própria, a cultura surda. (SALLES et al., 2004, p. 23-24).

Se, por um lado, a lusofonia tem como principal eixo a valorização da língua portuguesa articulada ao ensino dessa língua por meio do letramento e das questões que envolvem o bilinguismo, especialmente no caso das comunidades surdas, como aponta Salles et al. (2004), por outro lado, a maneira como as línguas de sinais funcionam no seio das comunidades surdas pertencentes ao contexto lusófono é algo que merece destaque. O sentimento de nacionalidade e de união promulgado pela lusofonia pode funcionar como um dispositivo que revela relações de colonização. Ou seja, a defesa e a implementação da língua portuguesa respaldada pelo argumento de língua de prestígio podem funcionar negativamente, marginalizando as demais línguas existentes no contexto multilíngue, especialmente nos países africanos. Severo e Makoni (2015, p. 57) afirmam que "a lusitanização é um dispositivo complexo e heterogêneo que envolveu a maneira como instituições, visões de mundo, religião e línguas portuguesas/europeias buscaram dominar e controlar regiões e povos tomados como colonizados”.

Nessa perspectiva, é comum observarmos que os discursos sobre as línguas de sinais e sobre a tradução e a interpretação no contexto lusófono emergem de forma tímida, ou seja, praticamente invisíveis, no que tange à circulação do conhecimento e das produções acadêmicas investigadas em Moçambique e no Brasil. ${ }^{4}$ Um exemplo disso ocorreu no ano de 2013, no XII Congresso Internacional do Instituto Nacional de Educação de

\footnotetext{
${ }^{4}$ Vale destacar a necessidade de estudos que investiguem as políticas linguísticas adotadas em Moçambique e no Brasil e, especialmente, o modo como eles influenciam na construção de políticas de tradução. Enquanto em Moçambique as discussões giram em torno da presença do multilinguismo, no Brasil há um forte debate sobre a imposição do monolinguismo. A questão fundamental dessa argumentação busca compreender se as políticas de tradução construídas nos dois países são similares, já que os universos linguísticos desses países são distintos, e ainda se a invisibilidade das atividades de tradução e de interpretação na cena pública sinalizaria a incipiente discussão sobre as demandas e a relevância das políticas de tradução?.
} 
Surdos, cujo tema foi a Educação de Surdos em Países de Língua Portuguesa. Ao consultarmos os anais do XII Congresso Internacional do Instituto Nacional de Educação de Surdos, a menção à tradução e à interpretação de línguas de sinais nos países lusófonos é pouco evidente.

A maioria dos trabalhos sobre tradução ou interpretação de línguas de sinais pertence ao Brasil e, em menor número, a Portugal. Nos anais desse evento, a tradução e a interpretação de línguas de sinais no contexto lusófono não aparece em destaque. Os números indicam vários trabalhos relacionados ao ensino de língua portuguesa ou a experiências de pessoas surdas com a educação bilíngue nos países da Comunidade dos Países de Língua Portuguesa.

Diante dessas considerações, este trabalho busca aproximar e discutir determinados marcos históricos importantes nas políticas linguísticas voltadas às línguas de sinais do Brasil e de Moçambique que afetam diretamente as decisões políticas direcionadas à tradução e à interpretação de línguas de sinais nesses países.

\section{As políticas linguísticas e as línguas de sinais: Libras e LSM}

Nos últimos anos, especialmente após a década de 1990, várias foram as ações sociais, culturais e acadêmicas em torno da Língua Brasileira de Sinais (Libras) e da Língua de Sinais de Moçambique (LSM), o que contribuiu para que ambas fossem reconhecidas como línguas de uso e de expressão das comunidades surdas. A seguir, recuperamos três elementos que são constituintes da história das políticas linguísticas em torno das línguas de sinais, tanto no Brasil quanto em Moçambique: os movimentos surdos e os movimentos de tradutores e intérpretes de línguas de sinais, a criação de cursos de graduação em Letras para formação de professores e de tradutores e intérpretes de línguas de sinais e, por último, os desafios à atuação dos tradutores e intérpretes de línguas de sinais .

\subsection{Os movimentos surdos e os movimentos de tradutores e intérpretes de línguas de sinais}

Historicamente, os movimentos de surdos estão entre os marcos determinantes da luta pelo reconhecimento das línguas de sinais. Esses movimentos tinham uma série de reivindicações de cunho educacional, linguístico, tradutório, cultural, dentre outras, 
como a garantia de direitos por meio de leis que assegurassem o acesso linguístico das pessoas surdas nos mais diversos espaços.

No Brasil, por exemplo, os movimentos surdos institucionalizaram-se por meio de algumas entidades representativas, dentre elas a Federação Nacional de Educação e Integração dos Surdos -FENEIS. Santos (2006, p. 23) afirma que "essa instituição é um marco de posição política dos surdos que exemplifica as tentativas que permeiam, desde sua fundação, a preocupação por um olhar diferente em relação aos surdos”. A FENEIS foi criada no final dos anos 1980 como uma organização nacional, respaldada pelas associações de surdos, com o objetivo principal de contribuir para a autonomia das pessoas surdas.

A atuação da FENEIS não se restringia apenas às pessoas surdas, mas durante muito tempo também se dedicou à estruturação, à certificação e à formação continuada de tradutores e intérpretes de Libras-Português. Em meados da década de 1990, o Departamento Nacional de Intérpretes da FENEIS era o órgão responsável pelas questões referentes à profissionalização dos tradutores e intérpretes de línguas de sinais. Nessa época, a formação de tradutores e intérpretes de Libras-Português era incipiente e ocorria por meio de cursos com curta duração, tal como explicam Quadros e Santos (2010). As autoras destacam que

\footnotetext{
[a]ssim, nestes primeiros momentos de formação dos TILS [tradutor-intérprete de língua de sinais], uma característica que marca tal período é a mudança de um espaço empírico e informal para uma atuação institucional do TILS. Mesmo com cursos livres, há efetivamente uma transição de uma atuação mais informal para uma atuação mais profissional que irá servir de base para o que está acontecendo hoje na formação destes profissionais. (QUADROS; SANTOS, 2010, p. 94).
}

Essa relação entre os movimentos surdos e a atuação/formação de tradutores e intérpretes de Libras-Português foi intensa nesse período histórico e não parece ser exclusiva do nosso país. Em Moçambique, os movimentos sociais para surdos se iniciaram no final da década de 1990 com a criação da Associação dos Familiares e Amigos de Surdos. No ano de 1999, surgiu a Associação dos Surdos de Moçambique (ASUMO), cuja finalidade principal era integrar o surdo na sociedade e zelar pelo seu bem-estar, promovendo ações concretas na comunidade com vista à reabilitação social e à integração dos 
surdos. Mesmo após 20 anos, o cumprimento desses objetivos é passível de críticas, dado que essas medidas ainda não foram efetivamente implementadas. Os obstáculos enfrentados na implementação de ações concretas em torno da comunidade surda afetam diretamente a atuação de tradutores e de intérpretes em Moçambique. Um exemplo disso foi citado no discurso apresentado na Semana Internacional de Surdos por Agostinho Fulitche, presidente da ASUMO.

\begin{abstract}
A Associação dos Surdos de Moçambique entende que o sector da educação ainda tem muito por fazer em prol dos seus membros, que continuam a ser excluídos. Outra questão levantada por esta agremiação é a falta de tradução das mensagens apresentadas pelos partidos e candidatos à presidente da República, durante este período de campanha. (FULITCHE, 2014, p.1, grifo nosso).
\end{abstract}

Diante do exposto, observa-se que a falta de tradutores e intérpretes de línguas de sinais é uma constante. De modo geral, na medida em que os serviços públicos contam com a presença de profissionais da tradução, as comunidades surdas têm a oportunidade de acessar linguisticamente espaços sociais e acadêmicos com maior grau de inserção e participação efetiva. Nesse sentido, um dos marcos importantes na visibilidade dos tradutores e intérpretes de línguas de sinais são as entidades representativas dessas categorias. Em Moçambique, a criação da Associação dos Intérpretes de Língua de Sinais, em 2006, contribuiu para dinamizar as atividades de interpretação e para destacar a visibilidade da atuação dos intérpretes no país.

Essa visibilidade foi notória em grandes centros urbanos, como nas cidades de Maputo, Beira e Nampula. Nessas cidades, as pessoas surdas começaram a usufruir dos serviços de tradução e interpretação oferecidos por profissionais competentes, qualificados, conhecedores de suas atribuições e dos preceitos do código de ética das categorias. Esses serviços, dependendo das demandas, podem ser oferecidos individualmente ou em equipes de tradutores ou de intérpretes. Por outro lado, nas zonas rurais, serviços de tradução ou de interpretação nem sempre estão disponíveis, pois há regiões do país onde as pessoas surdas não estão organizadas em comunidades, ou, quando estão, a língua de sinais ainda não está suficientemente difundida. 
No Brasil, os movimentos em torno das entidades representativas de tradutores e intérpretes de línguas de sinais tiveram início no ano de 2004, no qual foi criada a Associação dos Profissionais Tradutores/Intérpretes e Guia intérpretes de Língua de Sinais do Estado de São Paulo, fundada por Ricardo Sander. De acordo com Rocha (2013, p.15),

[a]pós este acontecimento, por meio da internet e de grupos de discussão
de intérpretes por todo o Brasil que "estavam isolados e se sentindo sozi-
nhos em seus locais de atuação" surgiram associações de intérpretes pelo
Brasil. Essas novas associações, chamadas de forma abreviada, de APILS,
surgiram em diferentes locais, como: APILMS (de Mato Grosso do Sul),
a APILDF (do Distrito Federal), a AGILS (do Rio Grande do Sul), a
APILCE (do Ceará), dentre outras. Algumas dessas associações logo se
fortaleceram, outras, contudo, tiveram enormes dificuldades para a orga-
nização.

Tal como frisa Rocha (2013), a fundação das associações de tradutores e intérpretes de língua de sinais distribuídas pelo Brasil contribuiu para a criação da Federação Brasileira das Associações dos Profissionais Tradutores e Intérpretes e Guia-Intérpretes de Língua de Sinais (FEBRAPILS), fundada em 22 de setembro de 2008, em Brasília. Segundo a FEBRAPILS (2016), os pilares que sustentam essa entidade são a formação inicial e continuada, a profissionalização e o engajamento político desses profissionais.

Esse conjunto de informações fornece elementos para refletir sobre um ponto crucial em relação ao aspecto histórico, qual seja, a atuação dos movimentos surdos na reivindicação do reconhecimento das línguas de sinais e na qualificação do acesso das pessoas surdas aos diversos espaços em nossa sociedade. As conquistas em torno da profissionalização de tradutores e intérpretes de língua de sinais e o reconhecimento legal da Libras (no caso do Brasil) contribuem para um desenvolvimento das políticas linguísticas das línguas de sinais.

Cabe ressaltar que essas temáticas que constituem a expansão das políticas linguísticas das línguas de sinais não podem ser analisadas de forma neutra, pois deliberações em torno das línguas são decisões políticas. Por exemplo, a eleição de determinados assuntos que irão compor as leis e decretos em torno de uma língua ilustra as relações de 
poder existentes para definir aquilo que deve permanecer e o que será excluído de tal material.

\subsection{O reconhecimento legal das línguas de sinais e a criação dos cursos de graduação}

As perspectivas sobre políticas linguísticas distinguem-se no modo como operacionalizam os planejamentos e nas suas concepções epistemológicas. Por exemplo, algumas dessas vertentes, como a defendida por Calvet (2007), afirma que o reconhecimento legal de uma língua é um passo importante para o planejamento linguístico. Outras, como aquelas de cunho crítico, representadas por Rajagopalan $(2003,2013)$ e Severo e Makoni (2015), colocam em discussão e problematizam os conceitos de política e de língua à luz de diferentes campos, como Sociologia, Antropologia, Filosofia e Direito. Considerando essas diferentes vertentes e os encaminhamentos históricos tomados em relação ao reconhecimento legal das línguas de sinais em Moçambique e no Brasil, temos a situação que descrevemos a seguir.

Em Moçambique, o direito à educação de surdos está respaldado na Constituição da República, no artigo 125, que se destina aos portadores de deficiência. No item 2 do referido artigo, o texto constitucional ressalta que “[o] Estado promove a criação de condições para a aprendizagem e desenvolvimento da língua de sinais"(MOÇAMBIQUE, 2004, p. 37). Apesar de ser mencionada na Constituição, a implementação das políticas linguísticas em torno da língua de sinais tem ocorrido de forma morosa em Moçambique. Uma das ações que merece destaque no contexto desse país é a criação do primeiro curso para formação de professores de Língua de Sinais e de tradutores e intérpretes. $\mathrm{O}$ curso de Licenciatura em Língua de Sinais de Moçambique (formação para o nível de graduação com habilitações para professores de surdos e para intérpretes de língua de sinais) iniciou-se no ano de 2014. Seu documento curricular preconiza o seguinte:

É no contexto do preceituado na Constituição da República, no Plano Estratégico da Educação e no Plano Estratégico da UEM [Universidade Eduardo Mondlane] que a Faculdade de Educação, procurando acomodar as políticas educativas inclusivas do Governo de Moçambique e do MINED [Ministério da Educação] em particular, se propõe a introduzir um curso de Licenciatura em Língua de Sinais Moçambicana (LLSM) no âmbito do seu plano de desenvolvimento. (DOCUMENTO CURRICULAR, 2014, p.5). 
A implementação de um curso de graduação dessa natureza colabora para a visibilidade da língua de sinais e para a formação de profissionais capacitados, sejam eles professores ou tradutores e intérpretes. Por outro lado, é comum que no percurso inicial de implementação, cursos como esse enfrentem desafios. Alguns desses obstáculos estão relacionados à infraestrutura, outros são de ordem linguística e cultural, além do desafio de lidar com um número insuficiente de pesquisadores mestres e doutores nas áreas de Linguística, Educação de Surdos ou Tradução e Interpretação de Línguas de sinais.

As características mencionadas acima também fizeram parte da implementação do curso de Licenciatura em Letras-Libras na modalidade a distância, criado no ano de 2006, pela Universidade Federal de Santa Catarina (UFSC) em parceria com outras instituições. Esse curso, dedicado à formação de professores de língua de sinais, em um primeiro momento deparava-se com uma estrutura institucional que não estava habituada com a língua de sinais. A parceria interna entre diferentes departamentos ${ }^{5}$ da UFSC e a parceria interinstitucional com diversas universidades e institutos federais contribuíram para a visibilidade da língua de sinais e para mudanças em algumas estruturas no meio acadêmico.

Posteriormente, no ano de 2008, foi fundado, também pela UFSC, o curso de Bacharelado ${ }^{6}$ em Letras-Libras, dedicado à formação de tradutores e intérpretes de língua de sinais. Também na modalidade a distância, o curso contava com uma rede de vários polos distribuídos em diferentes instituições, o que permitiu maior abrangência na formação desses profissionais. No contexto brasileiro, os cursos de Licenciatura e Bacharelado em Letras-Libras tiveram uma importância vital na institucionalização acadêmica da língua de sinais e na profissionalização dos professores e dos tradutores e intérpretes de língua de sinais.

No Brasil, cabe ressaltar que a emergência desses cursos e outras ações que promoveram a Libras estão atreladas ao reconhecimento legal dessa língua por meio da lei 10.436/2002 e sua consequente regulamentação por meio do decreto 5.626/2005. Ou seja, esses documentos legais respaldaram ações como a inclusão da Libras como disciplina curricular obrigatória dos cursos de licenciatura e de Fonoaudiologia, a formação

\footnotetext{
${ }^{5}$ Alguns professores do Departamento de Língua e Literatura Vernáculas (DLLV) e do Departamento de Língua e Literatura Estrangeiras (DLLE) fizeram parte da história dos cursos de Licenciatura e Bacharelado em Letras-Libras da UFSC.

${ }^{6}$ Para mais detalhes sobre a história dos cursos de Letras-Libras da UFSC, verificar Quadros (2015).
} 
do professor de Libras, a formação dos tradutores e intérpretes de Libras-Português, e a promoção do uso e da difusão da Libras e da língua portuguesa para o acesso das pessoas surdas à educação. Além disso, nessas normas está incluído o papel do poder público e das empresas que detêm concessão ou permissão de serviços públicos no apoio ao uso e à difusão da Libras, dentre outras especificações.

Essas ações cooperaram para uma mudança no status da Libras e no discurso sobre ela no meio acadêmico. Essa língua não se encontra mais restrita a determinados espaços sociais, tal como era em meados da década de 1990, ou somente utilizada pelas pessoas surdas. Atualmente, o uso da língua de sinais no ensino superior pelas pessoas surdas ou não surdas, a presença de tradutores e intérpretes de Libras-Português nesse meio e o desenvolvimento de inúmeras pesquisas na área de Linguística e de Estudos da Tradução colaboram para a qualificação da produção acadêmica referente a essa língua e, por extensão, para o aumento da sua visibilidade. Esses exemplos podem ser considerados marcos constitutivos do processo de institucionalização das políticas linguísticas relacionadas à Libras na sociedade brasileira.

Se, por um lado, a visibilidade das línguas de sinais contribuiu para mudanças em relação ao status dessas línguas e da forma como se concebem as pessoas surdas, especialmente na promoção, na difusão e na garantia de direitos linguísticos, por outro lado, discutimos, na próxima seção, alguns desafios que se impuseram na consolidação dessas políticas, como aqueles enfrentados em relação à tradução e à interpretação de línguas de sinais.

\subsection{Desafios contemporâneos na atuação de tradutores e intérpretes de línguas de sinais (Libras e LSM)}

Os desafios contemporâneos em torno da atuação de tradutores e de intérpretes de línguas de sinais tanto no Brasil quanto em Moçambique devem ser discutidos no âmbito das políticas linguísticas quanto às línguas de sinais. $\mathrm{O}$ desenho de políticas tradutórias que contemplem a formação continuada dos tradutores e intérpretes e as competências gerais e específicas que constituem as atividades desses profissionais, a implementação dos serviços de tradução e de interpretação de acordo com as demandas institucionais, e as ações políticas em torno da construção da carreira do profissional tradutor ou intérprete são alguns dos elementos que se destacam nesse debate. 
No Brasil, por exemplo, temos avanços significativos em torno do reconhecimento do tradutor e do intérprete de Libras-Português, como o capítulo V do Decreto $5.626 / 2005$, que trata especificamente da formação desse profissional. No entanto, é urgente em nosso país a necessidade de programas e currículos que ofereçam subsídios para a atuação desse profissional em contextos especializados, como nas áreas médica, jurídica e outras. Mesmo na área educacional, considerada uma das esferas com maior oferta de trabalho, a atuação do intérprete de Libras-Português encontra várias problemáticas, dentre elas as atribuições desse profissional, temática bastante discutida na literatura da área, conforme Lacerda (2010), Albres e Lacerda (2013), Albres (2015) e Francisco e Santos (2016).

Por outro lado, a contradição entre as leis e decretos que tratam sobre o tradutor e o intérprete de Libras-Português, no que tange às exigências desse profissional para atuação no mercado de trabalho, causa certas dificuldades no desenho de políticas tradutórias e, por consequência, na operacionalização dos trabalhos em torno da tradução e da interpretação. Um exemplo disso pode ser observado na regulamentação da profissão de tradutor e intérprete de Libras-Português no Brasil, a qual delibera em seu artigo $4^{\circ}$ que:

\footnotetext{
A formação profissional do tradutor e intérprete de Libras - Língua Portuguesa, em nível médio, deve ser realizada por meio de:

I - cursos de educação profissional reconhecidos pelo Sistema que os credenciou;

II - cursos de extensão universitária; e

III - cursos de formação continuada promovidos por instituições de ensino superior e instituições credenciadas por Secretarias de Educação. (BRASIL, 2010).
}

Ou seja, enquanto o Decreto 5.626/2005 aponta para a formação de nível superior para os profissionais da tradução e da interpretação, a lei que regulamenta a atuação desses profissionais determina formação com nível médio. Essas contradições legais são graves e desdobram-se em consequências complexas a serem administradas, especialmente, nas universidades federais. Os concursos públicos para tradutores e intérpretes de Libras-Português no serviço público federal, na sua maioria, são enquadrados, de acordo com o Plano de Carreira dos Cargos Técnico-Administrativos em Educação 
(PCCTAE), no cargo de classificação D7, cuja nomenclatura se chama "Tradutor e Intérprete de Linguagem de Sinais”. Santos (2015, p. 120) ressalta que: “ [...] atualmente, uma parcela mínima desses servidores está enquadrada no cargo de classificação E com a nomenclatura de Tradutor/Intérprete (com exigência de ensino superior)."

Essa temática sobre a regulamentação da profissão e os seus respectivos desdobramentos é um ponto que se destaca também na realidade de Moçambique. Nesse país, a regulamentação das atividades de tradução e interpretação são demandas profissionais urgentes, pois a criação de carreiras e níveis de atuação ainda não foram implementadas. Embora a LSM seja garantida pela Constituição da República, e seja reconhecida e usada como meio de comunicação no ensino formal dos alunos que frequentam as escolas especiais e inclusivas, essa língua não é regulamentada em Moçambique.

Essa situação pode ser um dos motivos para a falta de regulamentação para o exercício profissional de tradutores e intérpretes, o que pode abrir precedentes preocupantes. Um deles refere-se às diversas pessoas que podem atuar no mercado de trabalho sem uma diretriz profissional norteadora, ou ainda sem os quesitos básicos para atuação seja como tradutor ou intérprete. Diante dessa realidade, torna-se fundamental que investimentos governamentais sejam planejados e destinados à formação de profissionais qualificados para o exercício profissional.

Além disso, uma questão desafiadora para a atuação de tradutores e intérpretes de línguas de sinais tanto no Brasil quanto em Moçambique é a diferença entre os espaços urbano e rural e entre as demandas que derivam desses contextos. O espaço urbano (escolas, universidades, faculdades e outros) tem um maior número de vagas de trabalho para tradutores e intérpretes de Libras-Português. No Brasil, poucos registros teóricos tratam sobre diferentes línguas de sinais ou mesmo sobre o contexto rural como espaço de atuação para tradutores e intérpretes de Libras-Português, o que não quer dizer que não existam profissionais atuando nesses espaços. Rodrigues e Beer (2016) resgatam as contribuições de Brito (1995) e Vilhalva (2009), pois as autoras tratam, respectivamente, da Língua de Sinais Kaapor Brasileira e das línguas de sinais indígenas, denomi-

\footnotetext{
${ }^{7}$ O Plano de Carreira dos Cargos Técnico-Administrativos em Educação (PCCTAE) é dividido em cinco níveis de classificação (A, B,C, D e E). Essas cinco classes são conjuntos de cargos de mesma hierarquia, classificados a partir de alguns requisitos, como escolaridade. A escolaridade exigida no cargo D é o ensino médio.
} 
nadas como emergentes. Embora as autoras não tenham focado seus estudos nas questões de tradução e interpretação de línguas de sinais, é possível que tal prática ocorra de forma frequente nessas línguas, mas ainda não tenha sido objeto de pesquisa.

Nessa perspectiva, poder-se-ia afirmar que o contexto das línguas de sinais indígenas pode ser um espaço potencial para as pesquisas que investigam diferentes esferas de atuação para tradutores e intérpretes de língua de sinais no Brasil. Essas diferentes esferas de atuação são um elemento que se destaca nas realidades enfrentadas pelos tradutores e intérpretes de línguas de sinais do Brasil e de Moçambique. Em nosso país, as pesquisas apontam para a esfera educacional (nos diferentes níveis) como provedora de inúmeras vagas no mercado de trabalho para tradutores e intérpretes de Libras-Português.

No país africano, a maior incidência de trabalhos para tradutores e intérpretes de LSM parece ser visível em universidades. As demandas por tradutores e intérpretes de línguas de sinais fora do meio acadêmico é um ponto desafiador, visto que a população surda encontra-se em fase de empoderamento. Nesse sentido, a população surda busca criar ações que tenham visibilidade nacional em Moçambique, o que contribuirá para o desenvolvimento de postos de trabalho para tradutores e intérpretes.

Por outro lado, os desafios vão além da esfera educacional. Tal como destaca Delisle e Woodsworth (2003), os tradutores desempenham um papel fundamental no desenvolvimento das línguas nacionais, na emergência das literaturas nacionais, na disseminação do conhecimento, na produção de dicionários e dicionários especializados. Ou seja, tanto tradutores quanto intérpretes estão diretamente ligados ao desenvolvimento social, econômico, político e ideológico de um país. Segundo o Documento Curricular do curso de Licenciatura em Língua de Sinais Moçambicana (2013, p. 7):

[...] num programa desenvolvido em parceria com o MEC, o Instituto de Informática e Gestão, uma instituição privada sediada na Cidade de Maputo, promoveu de 15 de Outubro a 20 de Dezembro de 2007, o "Curso de Tradutores em Língua de Sinais", no qual foram capacitados 11 professores como intérpretes de LS. Provenientes de todas as províncias (um de cada), eles foram formados para, mais tarde, serem envolvidos nos programas de expansão e disseminação da LS nos seus locais de origem. 
Essa expansão e disseminação das línguas de sinais, além de contar com a atuação de tradutores e intérpretes, podem contribuir na sistematização da língua por meio de instrumentos linguísticos como gramáticas, glossários e dicionários. É o caso do Dicionário de Língua de Sinais de Moçambique produzido por (NGUNGA et al., 2013) no Centro de Estudos Africanos da Universidade Eduardo Mondlane. Essa obra é uma importante contribuição nos estudos sobre a LSM, pois os raros dicionários existentes no país datavam de 1995 e 2004, com menos de 1.000 entradas (palavras/sinais).

Contudo, a grande maioria dos dicionários mencionados foram publicados no formato impresso. Ou seja, o par de consultas é feito por palavras na língua portuguesa e a saída por meio de fotografias, o que torna a consulta mais estática, pois não permite a descrição dos movimentos, variação dos elementos não manuais e expressões faciais. Zandamela (2015) propôs um protótipo para a produção de um dicionário digital da Língua de Sinais de Moçambique (DDLSM). Nesse protótipo, a entrada poderia ser consultada por palavras na língua portuguesa e as saídas seriam disponibilizadas por meio da imagem do referente (se existir) e a definição do conceito/significado, numa perspectiva de software de instalação e, posteriormente, em uma plataforma on-line.

Por outro lado, no Brasil, as contribuições dos dicionários, glossários especializados e bancos terminológicos para a atuação de tradutores e intérpretes de LibrasPortuguês foram explorados por alguns autores. Tuxi e Felten (2014) tratam do glossário terminológico na formação do tradutor e Oliveira (2010) discute sobre o uso do glossário no curso de Letras-Libras da UFSC como ferramenta para formação/consulta de tradutores. De modo geral, no Brasil, várias pesquisas e materiais foram desenvolvidos, especialmente no campo dos dicionários ou glossários terminológicos sobre a Libras. Alguns desses trabalhos são: Linguagem das Mãos, Dicionário Digital do INES [Instituto Nacional de Educação de Surdos], Dicionário enciclopédico ilustrado trilingue da língua de sinais brasileira e outros. A relevância dos glossários e dicionários na atuação dos tradutores e intérpretes é abordada por Santos (2013):

Do nosso ponto de vista, recursos terminológicos (glossários e banco de dados) desempenham um papel fundamental e colaboram para a preparação da interpretação de língua de sinais nos mais diversos contextos. Outro ponto que merece destaque é o fato de que, se o intérprete se familiariza com a terminologia de forma prévia, o esforço cognitivo empre- 
gado no ato interpretativo (na maioria das vezes, interpretação simultânea) poderá ser mais bem gerenciado durante o processo tradutório. Dessa forma, o profissional poderá tomar decisões com maior grau de segurança e competência referencial mais elaborada, evitando estratégias improvisadas, muito comuns em casos de desconhecimento do conteúdo a ser interpretado. (SANTOS, 2013, p. 90).

Diante dessas considerações, um elemento fundamental para a consolidação da atuação dos tradutores e intérpretes de língua de sinais do Brasil e de Moçambique é a formação por contextos específicos. A formação especializada é um dos principais desafios contemporâneos na atuação desses profissionais, o que sugere a necessidade de uma política de tradução que contemple tais demandas no investimento governamental desses países. Por exemplo, em alguns espaços da esfera jurídica é comum relatos de intérpretes de línguas de sinais que atuam voluntariamente, não buscando seus direitos profissionais ou mesmo desconhecendo-os.

No caso brasileiro, a Recomendação no 27 do Conselho Nacional de Justiça orienta a nomeação de tradutor e intérprete de língua de sinais sempre que figurar pessoa surda no processo. A previsão de um orçamento inadequado, a falta de infraestrutura para realização da interpretação de línguas de sinais, os obstáculos enfrentados frente às posturas do Judiciário (especialmente aquelas relacionadas à falta de conhecimento sobre o papel do tradutor ou do intérprete), e as técnicas e estratégias para atuação do intérprete de Libras no espaço jurídico podem contribuir para que o profissional abandone a atividade em tal esfera, ou ainda que busque outros trabalhos com melhores condições.

Por fim, investir no ensino de tradutores e de intérpretes de línguas de sinais por contextos específicos não é somente agir a favor desses profissionais, mas qualificá-los para o melhor atendimento, assim como garantir os direitos das pessoas surdas nos diversos espaços sociais e científicos.

\section{Considerações finais}

A tradução e a interpretação de línguas de sinais apresentam-se como um campo fértil para expandir as discussões sobre as políticas linguísticas. A linha argumentativa que pautou este texto foi a defesa da construção de um diálogo entre Brasil e Moçambique à luz de alguns marcos históricos sobre a tradução e a interpretação de línguas de sinais, 
dando ênfase a dois tópicos. O primeiro deles é a aproximação entre os dois países e algumas implicações da tradução e interpretação de línguas de sinais dentro do cenário lusófono; o outro é as políticas linguísticas e as línguas de sinais (Libras e LSM). Nesta última etapa, abordam-se reflexões sobre os movimentos surdos e os movimentos de tradutores e intérpretes de línguas de sinais, o reconhecimento legal das línguas de sinais, a criação dos cursos de graduação, e os desafios contemporâneos para a atuação desses profissionais da tradução.

Com base nas discussões apresentadas neste trabalho foi possível verificar que a interlocução entre Brasil e Moçambique no que se refere à tradução e interpretação de línguas de sinais é incipiente. Talvez essa observação a respeito da incipiência seja explicada pela grande quantidade de ações e projetos voltados às línguas de sinais em articulação com a produção acadêmica norte-americana ou europeia. Com a criação dos cursos de graduação em Letras-Libras (licenciatura e bacharelado) em diversas universidades brasileiras e com o curso de Licenciatura em Língua de Sinais de Moçambique na Universidade Eduardo Mondlane, as possibilidades de aproximação entre os dois países aumentam consideravelmente. Ou seja, projetos de cooperação interinstitucional, dentre outras atividades, podem ser construídos a favor da qualificação dos serviços oferecidos na tradução e na interpretação de línguas de sinais nesses países.

Diante desse cenário, sugere-se que os tradutores e intérpretes de línguas de sinais do Brasil e de Moçambique registrem e sistematizem suas práticas cotidianas, especialmente aquelas voltadas para os desafios enfrentados em diferentes esferas da interpretação, tais como fóruns, tribunais, clínicas, hospitais e demais órgãos públicos. Esses materiais podem auxiliar na visibilidade desse profissional e contribuir para o aumento da participação da comunidade surda em diferentes estruturas públicas do governo.

Além disso, a interlocução entre tradutores e intérpretes de línguas de sinais e de línguas orais é vital para um espaço com maior visibilidade para os profissionais da tradução. Nesse quesito, um argumento fundamental é elevar as discussões em torno das línguas nacionais (em Moçambique), incluindo na pauta a tradução e a interpretação, sejam elas de línguas de sinais ou orais. Em entrevista concedida ao jornal @Verdade, Ngunga (2014) narra que

[e]m Moçambique, a língua materna de determinadas pessoas - 10\% - é o português. No entanto, há pessoas que, não falando o português, é-lhes recusada a possibilidade de sobreviver porque os médicos, por exemplo, 
não se comunicam com elas nas suas línguas. Por essa razão, invariavelmente, os doentes não explicam devidamente de que padecem. Quando o paciente e o médico não partilham a mesma língua, o doente corre sérios riscos de vida. A língua é um meio importante que, se bem utilizado, pode salvar a nossa vida, mas também nos pode matar. (NGUNGA, 2014, $\mathrm{s} / \mathrm{p})$.

A situação apresentada no depoimento acima nos mostra a necessidade real de uma discussão e um planejamento de políticas de tradução que possam atender de forma satisfatória aqueles cidadãos que não compartilham o idioma oficial do seu país. Considerando que o depoimento ilustra uma situação na esfera médico-hospitalar, tal discussão poderia ser encaminhada às entidades representativas dos profissionais tradutores e intérpretes. O papel das associações profissionais, segundo Queiroz (2011),“[...] foi e tem sido decisivo para a definição de requisitos e qualificações educacionais para intérpretes-médicos”. (QUEIROZ, 2011, p. 43).

As reflexões tecidas neste texto constituem-se em um primeiro passo para colocar em cena aspectos relacionados à tradução ou à interpretação que estão praticamente invisíveis nesses contextos marcados pelo multilinguismo. Por fim, sugere-se que os tradutores e intérpretes de línguas de sinais tanto do Brasil quanto de Moçambique realizem esforços junto às instâncias governamentais para que elas incluam nas pautas reivindicatórias e destinem investimentos: (i) à formação por contextos especializados de tradução e interpretação, (ii) à qualificação dos serviços ofertados por esses profissionais e (iii) à formação de recursos humanos nos níveis de mestrado e doutorado a fim de fortalecer a pesquisa sobre tradução e interpretação de línguas de sinais na Comunidade dos Países de Língua Portuguesa.

\section{Referências}

ALBRES, Neiva A. ; LACERDA, Cristina B. Interpretação educacional como campo de pesquisa: estudo bibliométrico de publicações internacionais e suas marcas no campo nacional. Cadernos de Tradução, Florianópolis, v. 1, n. 31, p. 179-204, abr. 2013. Disponível em: https://periodicos.ufsc.br/index.php/traducao/article/view/21757968.2013v1n31p179. Acesso em: 05 jul. 2016.

ALBRES, Neiva. A. Intérprete educacional: políticas e práticas em sala de aula inclusiva. 1. ed. São Paulo: Harmonia, 2015. 144p. 
BEHARES, Luis E. Notas sobre la noción de derechos lingüísticos ¿quién es su titular? Revista Digital de Políticas Lingüísticas, año 4, v. 4, p. 37-53, set. 2012.

BRASIL. Lei no 10.436, de 24 de abril de 2002. Dispõe sobre a Língua Brasileira de Sinais - Libras e dá outras providências. Diário Oficial da União, República Federativa do Brasil, Atos do Poder Legislativo, Brasília, DF, 25 abr. 2002, n. 79, ano CXXXIX, Seção 1, p. 23. Disponível em:

http://www.planalto.gov.br/ccivil_03/leis/2002/L10436.htm. Acesso em: 05 dez. 2016.

Decreto no 5.626, de 22 de dezembro de 2005. Regulamenta a Lei no 10.436, de 24 de abril de 2002, que dispõe sobre a Língua Brasileira de Sinais - Libras, e o art. 18 da Lei no 10.098, de 19 de dezembro de 2000. Diário Oficial da União, República Federativa do Brasil, Atos do Poder Executivo, Brasília, DF, 23 dez. 2005, no 246, ano CXLII, Seção 1, p. 28-30. Disponível em:

http://www.planalto.gov.br/ccivil_03/_ato2004-2006/2005/decreto/d5626.htm Acesso em: 05 dez. 2016.

. Lei no 12.319 , de 01 de setembro de 2010. Dispõe sobre a regulamentação da profissão de Tradutor e Intérprete da Língua Brasileira de Sinais - Libras. Diário Oficial da União, República Federativa do Brasil, Atos do Poder Legislativo, Brasília, DF, 2 set. 2010. No 169, ano CXXXIX, Seção 1, p. 43. Disponível em:

<http://www.planalto.gov.br/ccivil_03/_Ato2007-2010/2010/Lei/L12319.htm Acesso em: 05 dez. 2016.

. Recomendação n 27, de 16 de dezembro de 2009. Dispõe sobre orientação da nomeação do tradutor e intérprete de língua de sinais. Conselho Nacional de Justiça. Diário Oficial da União, República Federativa do Brasil, Atos do Poder Legislativo, Brasília, DF. 25 jan. 2010. Seção 1, p. 107, e DJE/CNJ no 15/2010, de 25/1/10, p. 2-4. Disponível em: http://www.cnj.jus.br/atos-normativos?documento=873. Acesso em: 05 dez. 2016.

BRITO, Lucinda F. Por uma Gramática de Língua de Sinais. Rio de Janeiro: Tempo Brasileiro, 1995.

CALVET, Louis-Jean. As políticas línguísticas. Parábola Editorial. São Paulo, 2007,160 p. CAPOVILLA, Fernando C.; RAPHAEL, Walkiria D.; MAURÍCIO, Aline C. Novo DeitLibras: dicionário enciclopédico ilustrado trilíngue. Edusp, São Paulo, 2009.

CHRYSTELLO, Chrys. Anuário Colóquios da Lusofonia anos 2002-2010. Estudos Lusófonos Língua e Literatura. Edição AICL, Porto, 2002. 215p.

DELISLE, Jean; WOODSWORTH, Judith. Os tradutores na história. Tradução: Sérgio Bath. 1. ed. São Paulo: Ática, 2003. 
DOCUMENTO CURRICULAR. Currículo do Curso de Licenciatura em Língua de Sinais Moçambicana, Universidade Eduardo Mondlane, 2013.

FEBRAPILS. Descrição sobre a Federação Brasileira das Associações dos Profissionais Tradutores e Intérpretes e Guia-intérpretes de Língua de Sinais. Disponível em: http://www.febrapils.com.br/p/quem-somos.html. Acesso em: 03 jul. 2016

FRANCISCO, Camila; SANTOS, Silvana A. Editais de concursos públicos: análises das atribuições dos intérpretes educacionais Libras-Português. Revista Sinalizar (UFG), v.1, p. 48-64, 2016.

FULITCHE, Agostinho. Discurso apresentado na Semana Internacional de Surdos, 2014. Disponível em: http://opais.sapo.mz/index.php/sociedade/45sociedade/30972-mocambicanos-celebram-semana-internacional-de-surdos.html.

Acesso em: 03 jul. 2016

INES. In: Anais do Congresso: a educação de surdos em países de Língua Portuguesa / [XII Congresso Internacional do INES e XVIII Seminário Nacional do INES]. - Rio de Janeiro: INES, Departamento de Desenvolvimento Humano, Científico e Tecnológico, 2013.719p.

LACERDA, Cristina. Tradutores e intérpretes de Língua Brasileira de Sinais: formação e atuação nos espaços educacionais inclusivos. Cadernos de Educação (UFPel), v. 36, p. 133-153, 2010.

MOÇAMBIQUE. Constituição. Constituição da República de Moçambique. Senado Federal, 2004, 97p.

NGUNGA, Armindo. et al. Dicionário da língua de sinais de Moçambique. Maputo: Centro de Estudos Africanos (CEA), UEM. 2013.501 p.

. Três perguntas ao Doutor Ngunga. Entrevista concedida ao Jornal @Verdade em 27 de fevereiro de 2014. Disponível em: http:/ / www.verdade.co.mz/cultura/44375tres-perguntas-ao-doutor-ngunga. Acesso em: 03 jul. 2016.

OATES, Eugenio. Linguagem das Mãos. Rio de Janeiro: Gráfica Editora S.A. COLTED, 1969.

OLIVEIRA, Janine. Glossário Letras-Libras como ferramenta para formação/consulta de tradutores. Anais do IV Congresso Nacional de Pesquisas em Tradução e Interpretação de Libras e Língua Portuguesa Universidade Federal de Santa Catarina, 2010. p.1-7.

QUADROS, Ronice M. Letras-Libras: ontem, hoje e amanhã. Florianópolis: Editora da UFSC, 2015.

QUADROS; Ronice M; SANTOS, Silvana A. O tradutor-intérprete de língua de sinais no Brasil: Ontem, hoje e amanhã. Revista LSI - Lengua de Señas e Interpretacion, v. 1, p. 91-114, 2010. 
QUEIROZ, Mylene. Interpretação médica no Brasil. 134 p. Dissertação (Mestrado) Universidade Federal de Santa Catarina, Centro de Comunicação e Expressão, Programa de Pós-Graduação em Estudos da Tradução, Florianópolis, SC, 2011.

RAJAGOPALAN, Kanavillil. Por uma lingüística crítica. São Paulo: Parábola Ed., 2003.

. Política Linguística: do que é que se trata, afinal? In: Nicolaides, C. et. al. (Org.). Política e Políticas Linguísticas. SP: Pontes, 2013. [p. 19-42].

RODRIGUES, Carlos H.; BEER, Hanna. Direitos, políticas e línguas: divergências e convergências na/da/para educação de surdos. Educação e Realidade, v. 41, p. 661-680, 2016.

ROCHA, Valquíria. A atuação do intérprete de Libras em escolas no Brasil: processos históricos. 22f. Trabalho de Conclusão de Curso - Universidade Estadual de Maringá, Maringá-PR, 2013.

SALLES, Heloisa et al. Ensino de Língua Portuguesa para Surdos: Caminhos para a Prática Pedagógica. Brasília: MEC, 2004.v. 2.

SANTOS, Silvana A. Intérpretes de língua brasileira de sinais: um estudo sobre as identidades. Florianópolis, 2006. v, 188 f. Dissertação (Mestrado) - Universidade Federal de Santa Catarina, Programa de Pós-Graduação em Educação, 2006.

- Tradução/interpretação de língua de sinais no Brasil: uma análise das teses e dissertações de 1990 a 2010.2013. 313 p. Tese (Doutorado) - Universidade Federal de Santa Catarina, Centro de Comunicação e Expressão, Programa de Pós-Graduação em Estudos da Tradução, Florianópolis, 2013.

. A implementação do serviço de tradução e interpretação de libras-português nas universidades federais. Cadernos de Tradução, Florianópolis, v. 35, n. 2, p. 113-148, out. 2015.

SEVERO, Cristine; SITOE, Bento; PEDRO, José. Estão as línguas nacionais em perigo? São Paulo: Escolar Editora, 2014.

; MAKONI, Sinfree. B. Políticas Linguísticas Brasil-África: Por uma perspectiva crítica. 1. ed. Florianópolis: Insular, 2015. v. 1. 136p.

VILHALVA, Shirley. Mapeamento das Linguas de Sinais Emergentes: um estudo sobre as comunidades linguísticas Indígenas de Mato Grosso do Sul. Thesis (MSc in Linguistics) Programa de Pós-Graduação em Linguística - Centro de Comunicação e Expressão. Universidade Federal de Santa Catarina, 2009.

TUXI, Patrícia; FELTEN, Eduardo. Glossário terminológico na formação do tradutor. Anais do IV Congresso Nacional de Pesquisas em Tradução e Interpretação de Libras e Lingua Portuguesa. Universidade Federal de Santa Catarina, 2014, p.1-9. 
ZANDAMELA, Nehemia. Desenvolvimento de dicionário digital da Língua de Sinais de Moçambique: estudo de caso nas escolas especiais e inclusivas da cidade de Maputo. Maputo: Instituto Superior Monitor, 2015, 71p.

Data de submissão: 28/07/2016

Data de aceite: $15 / 08 / 2016$ 